\title{
A Scoping Review on Palliative Care: Knowledge and Attitude of Nurses
}

\author{
Nada Mohamad Aljehani*, Nahed Ahmed Mersal and Fatmah Alsharif \\ Department of Medical Surgical Nursing, Faculty of Nursing, King Abdulaziz University, Saudi Arabia
}

\begin{abstract}
Background: Palliative care is an essential aspect of care for advanced life-threatening illnesses. It involves holistic care that helps improve the quality of life for chronically ill patients. Palliative care is not meant to cure disease. Instead, it focuses on alleviating the burden of symptoms, easing the discomfort and stress that accompanies living with a life-threatening disease. The attitudes and knowledge of nurses play a vital role in the delivery of palliative care. Nurses should have a positive attitude and a good knowledge of palliative care. This review aims to identify, synthesize, and appraise the relevant evidence on nurses' level of knowledge and attitude toward palliative care and factors associated with such knowledge and attitude.
\end{abstract}

Methods: A literature search was conducted using several databases: CINAHL, PubMed, MEDLINE, and ScienceDirect. The search was limited to publications written in English between 2016 and 2020 using the search terms "nurses' knowledge," or / and "attitude" AND "palliative care."

Results: 12 studies were identified, analyzed, and synthesized in this review. All studies were quantitative, cross sectional. The finding demonstrates a general lack of sufficient knowledge on palliative care among nurses; however, nurses' attitudes toward palliative care were positive. Factors found to affect nurse's knowledge and attitude regarding palliative care included age, educational level, years of experience, and education/training in palliative care.

Conclusion: This review demonstrates a gap on nursing knowledge about palliative care. Nurses have inadequate knowledge of palliative care, suggesting a need for increased attention to this subject. It is necessary to Incorporate palliative care education/ training in nursing curricula and establish regular/continuous professional education courses on palliative care by the national health policies. In contrast to the negative findings regarding knowledge, nurses' attitudes towards palliative care were favorable. The need to implement strategies to improve knowledge as well as attitudes is necessary. Therefore, further research is required to develop interventions that improve knowledge and attitudes toward palliative care among nurses.

\section{INTRODUCTION}

The rise of chronic non-communicable diseases and an aging population have contributed to a rapid increase in the global demand for palliative care WHO [1]. According to WHO's 2014 global atlas of palliative care reported that $40-60 \%$ of deaths required palliative care. Cardiovascular disease (38.5\%) and cancer (34\%) were among the most common adult diseases requiring palliative care WPCA \&WHO [2].

Palliative care (PC) is a holistic medical approach that aims to improve the quality of life of people with chronic, terminal, or life-limiting diseases WHO [1]. This care approach primarily acts by applying prevention strategies and offering relief from suffering through early assessment and identification, while offering treatment for pain and other problems to include spiritual, psychosocial, and physical problems Ajisegiri [3]; Etafa [4].

Quick Response Code:

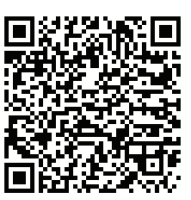

Address for correspondence: Nada Mohamad Aljehani, Medical Surgical Nursing, Faculty of Nursing, King AbdulAziz University, Saudi Arabia

Received: February 18, $2021 \quad$ Published: March 01, 2021

How to cite this article: Nada MA, Nahed AM, Fatmah A. A Scoping Review on Palliative Care: Knowledge and Attitude of Nurses. 2021- 3(2) OAJBS.ID.000259. DOI: 10.38125/OAJBS.000259 
The PC goal is to preserve the best possible quality of life for as long as possible. PC neither postpones nor hastens death; instead, it focuses on compassionate care for patients and their relatives to reduce their suffering Ajisegiri [3]; WHO [1].

PC is not constrained to any specific age, disease, or setting. It can be provided for patients of any age at any stage of illnesses who suffer from chronic, life-threatening conditions and can be provided alone or along with specific curative treatment WPCA \& WHO [2]

PC requires a collaborative multidisciplinary team comprised of health professionals from various fields, such as physicians, nurses, social workers, and other specialists, working together to meet the individual needs of each patient. Nurses are among the most valuable members of a PC team-they play an essential role in providing physical, functional, social, and spiritual dimensions of care Ansari [5].

The most crucial factors that influence the successful delivery of PC are the knowledge, attitudes, experiences, and beliefs of the health care professionals, especially nurses Gopal [6]. Extensive knowledge and positive attitude about PC enable nurses to provide high-quality care for chronically ill patients J Kim [7]; Paknejadi [8]; Wilson [9]; Zeru [10]; Aboshaiqah [11]. If nurses are well-educated about palliative care, their efficacy, attitudes, comfort level, and perceptions will be improved, and they will provide a more positive experience for patients and their families Goris [12].

Despite this fact, nurses often feel unprepared to offer PC Etafa [4]; Aboshaiqah [11]; J Kim [7]; Schnell H [13]; S Kim [14]; Ajisegiri [3]. Lack of knowledge, positive attitude, and practical skills among nurses was identified as a common barrier to providing the optimal level of PC. Thus, this comprehensive review aimed to identify, appraise, and synthesize relevant evidence (articles) that assesses nurses' knowledge of and attituded toward PC. This review will provide recommendations for future interventions in the policy, nursing education, and practice to increase the quality of PC services, and therefore the quality of life of patients in need of these care.

\section{METHODS}

\section{Search Strategy}

Relevant studies were retrieved from several electronic databases through extensive searches. The databases mined for research were CINAHL, PubMed, MEDLINE, and Science Direct. The keywords used to search were palliative care, nurse knowledge, attitude. The search terms were presented in various combinations to yield the best results and ensure a comprehensive search. When search terms were combined, the Boolean operators 'OR' and 'AND' were used.

\section{Inclusion and Exclusion Criteria}

Inclusion and exclusion criteria were developed and determined to identify the most relevant articles and guide the selection process. The search was limited to publications in English language. To seek an updated literature, the publications' date was specified to ranges for 2016 to 2020 and were primarily full text articles. Articles were excluded if studies in which the participants were nursing students or other healthcare practitioners such as physicians rather than nurses. Articles found not to be relevant or appropriate after thorough review were rejected.

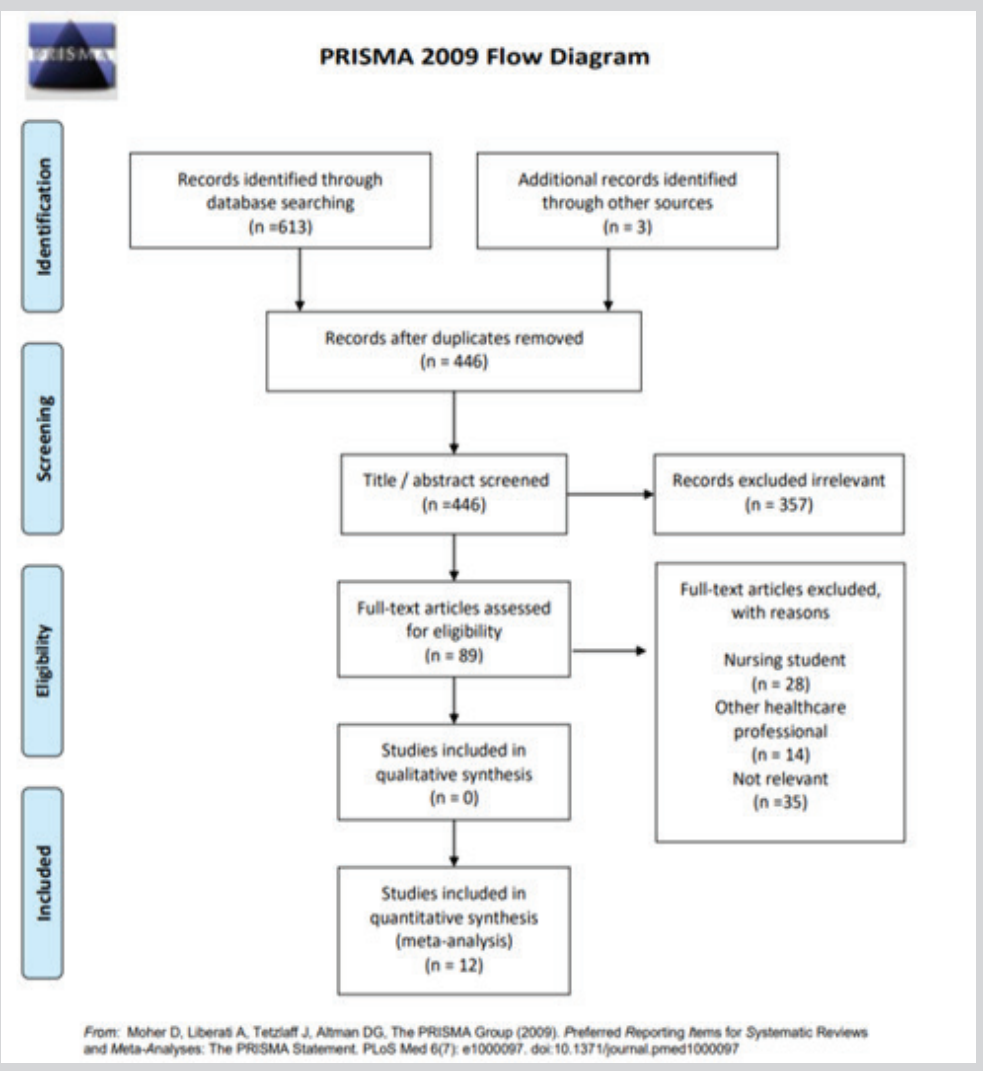

Figure 1: PRISMA Flow Diagram 


\section{Selection of the Studies}

The search strategy described above identified many articles. Based on inclusion and exclusion criteria, the final selection of studies was obtained. The identified articles were screened using PRISMA "preferred reporting items for systematic reviews and meta-analysis" flow diagram (Figure 1).

\section{Data Analysis}

A review matrix was used to represent the selection of studies and their characteristics (Appendix 1). The matrix summarizes study locations, aims, designs, samples, tools, results, and conclusions.

Appendix 1: Data extraction table/ Review matrix.

\begin{tabular}{|c|c|c|c|}
\hline $\begin{array}{l}\text { Study Citation } \\
\text { (Author/S, Year of } \\
\text { Publication. Study } \\
\text { Country }\end{array}$ & Study Aim/ Purpose & $\begin{array}{c}\text { Participants and Sample } \\
\text { Size }\end{array}$ & Main Findings/ Result \\
\hline Kim S, Lee K, Kim S (2020) & $\begin{array}{l}\text { To describe the PC knowledge, } \\
\text { attitude, confidence, and } \\
\text { educational needs in non } \\
\text {-oncology nurses. }\end{array}$ & $\begin{array}{l}\text { Nurses in general wards and } \\
\text { ICU }\end{array}$ & $\begin{array}{l}\text { Nurses' PC knowledge was low and attitude } \\
\text { toward PC was moderate. Knowledge was } \\
\text { significantly correlated with attitude. PC training } \\
\text { was a significant factor that influence nurses' } \\
\text { confidence. }\end{array}$ \\
\hline $\begin{array}{l}\text { Schnell Hoehn K, Estrella } \\
\text { Holder E, Avery L (2017) } \\
\text { Canada }\end{array}$ & $\begin{array}{l}\text { To assess the PC knowledge } \\
\text { among cardiac nurses }\end{array}$ & $\begin{array}{l}\text { Nurses in cardiology, coronary } \\
\text { care, cardiac surgery, or } \\
\text { intensive care cardiac surgery } \\
\text { unit }(\mathrm{N}=76)\end{array}$ & $\begin{array}{l}\text { The PCQN mean score was } 15 \text { out of } 20 \text { points. } \\
\text { Misconceptions existed related to the palliative } \\
\text { care philosophy, pharmacology }\end{array}$ \\
\hline $\begin{array}{l}\text { Zeru T, Berihu H, Gerensea H, } \\
\text { Teklay G, Teklu T, Gebrehiwot } \\
\text { H (2020) Ethiopia }\end{array}$ & $\begin{array}{l}\text { To assess nurse's knowledge } \\
\text { about and attitude towards PC } \\
\text { and factors associated with it. }\end{array}$ & $\begin{array}{c}\text { Nurses in general wards } \\
\text { at selected governmental } \\
\text { hospital in Ethiopia }(\mathrm{N}=355)\end{array}$ & $\begin{array}{l}\text { Only (62.8\%) had good knowledge out of the } \\
\text { entire participants, and (56.3\%) had a favorable } \\
\text { attitude towards PC. }\end{array}$ \\
\hline $\begin{array}{l}\text { Kim JS, Kim J, Gelegjamt D } \\
\text { (2020) Mongolia }\end{array}$ & $\begin{array}{l}\text { To examines nurse's knowledge } \\
\text { of PC, attitude towards caring of } \\
\text { dying, and self-efficacy. }\end{array}$ & oncology nurses $(\mathrm{N}=141)$ & $\begin{array}{l}\text { The PCQN score was } 8.0 / 20 \text { indication low level } \\
\text { especially in Psychosocial spiritual care domain. } \\
\text { While positive attitude toward PC was reported } \\
\text { in } 69 \%\end{array}$ \\
\hline $\begin{array}{c}\text { Paknejadi F, Hasavari F, } \\
\text { Khaleghdoost Mohammadi } \\
\text { T, Kazemnejad Leili E (2019) } \\
\text { Iran }\end{array}$ & $\begin{array}{l}\text { To examine the nurse's PC } \\
\text { knowledge and contributing } \\
\text { factors. }\end{array}$ & $\begin{array}{l}\text { Nurses from different } \\
\text { departments }(\mathrm{N}=280)\end{array}$ & $\begin{array}{c}\text { The Mean } \pm \text { SD score of PC knowledge was } \\
7.86 \pm 2.16 \text { indicating lack of and deficient PC } \\
\text { knowledge. }\end{array}$ \\
\hline $\begin{array}{l}\text { Wang L, Li C, Zhang Q, Li Y } \\
\text { (2018) China }\end{array}$ & $\begin{array}{l}\text { To examine attitudes of } \\
\text { nurses to caring for dying, and } \\
\text { relationships between nurses' } \\
\text { demographic data and attitudes } \\
\text { towards caring for dying. }\end{array}$ & $\begin{array}{l}\text { Nurses from general } \\
\text { departments }(\mathrm{N}=70)\end{array}$ & $\begin{array}{l}\text { The mean score of the FATCOD items was } 95.62 \text {. } \\
\text { Factors that influence nurses' attitudes towards } \\
\text { the care of dying was education, fears of death, } \\
\text { professional title, and experience with death or } \\
\text { dying patients. }\end{array}$ \\
\hline $\begin{array}{l}\text { Etafa W, Wakuma B, Fetensa } \\
\text { G, Tsegaye R, Abdisa E, Oluma } \\
\text { A, Takele T (2020) Ethiopia }\end{array}$ & $\begin{array}{l}\text { To measure knowledge and } \\
\text { attitude toward PC or ENLC. }\end{array}$ & $\begin{array}{l}\text { Nurses working in public } \\
\text { hospitals }(\mathrm{N}=422)\end{array}$ & $\begin{array}{l}\text { The result indicated that the majority of nurses } \\
\text { had an insufficient knowledge about PC. while } \\
\text { the scores of FATCOD showed a positive attitude } \\
\text { toward PC with } 52 \% \text { of study sample excited } \\
\text { to care for such patient and their relatives. } \\
\text { Nurses who had joined training on PC or had } \\
\text { PC experience were associated with better PC } \\
\text { knowledge. }\end{array}$ \\
\hline Aboshaiqah AE (2019) KSA & $\begin{array}{l}\text { To evaluate the PC knowledge } \\
\text { amid nurses and identify the } \\
\text { factors that affects knowledge. }\end{array}$ & $\begin{array}{l}\text { Nurses from } 2 \text { hospitals } \\
\qquad(\mathrm{N}=336)\end{array}$ & $\begin{array}{l}\text { The score of PCQN was } 8.88 \text { which indicate } \\
\text { insufficient PC knowledge. Speciality of the } \\
\text { hospital, the age, and receiving training / } \\
\text { education about PC were indicated as significant } \\
\text { factors that affect the PC knowledge level. }\end{array}$ \\
\hline Vu (2019) Vietnam & $\begin{array}{l}\text { To assess knowledge and attitude } \\
\text { toward PC for the geriatric amid } \\
\text { health professionals }\end{array}$ & $\begin{array}{c}124 \text { nurses and } 37 \text { doctors. } \\
\text { Total of } 161 \text { geriatric health } \\
\text { professionals }\end{array}$ & $\begin{array}{l}\text { The result highlight inadequate knowledge about } \\
\text { PC. low score was reported in pain/symptom } \\
\text { management. The age and experience were } \\
\text { associated with PC knowledge }\end{array}$ \\
\hline Abate (2019) Ethiopia & $\begin{array}{l}\text { To measure knowledge, attitude, } \\
\text { and factors towards EOLC }\end{array}$ & $\mathrm{N}=331$ Nurses & $\begin{array}{c}\text { Nurses' knowledge was low while the majority of } \\
\text { the sample have favorable attitude. }\end{array}$ \\
\hline Wilson (2016) Ireland & $\begin{array}{l}\text { To examines the PC knowledge } \\
\text { and attitudes towards caring for } \\
\text { the dying patient }\end{array}$ & $\begin{array}{c}(\mathrm{N}=97) \text { Nurses in older people } \\
\text { care settings }\end{array}$ & $\begin{array}{l}\text { The study conclude that nurses have moderate } \\
\text { knowledge level regarding PC. Attending (ECEPC) } \\
\text { was a significant difference in PC knowledge } \\
\text { scores. years of experience enhanced level of } \\
\text { knowledge and attitudes towards PC. }\end{array}$ \\
\hline Ajisegiri (2019) Nigeria & $\begin{array}{l}\text { To assesses PC knowledge, } \\
\text { attitude and practice for } \\
\text { healthcare worker who is care } \\
\text { for patient living with HIV/ } \\
\text { AIDS(PLWHA) }\end{array}$ & $\begin{array}{l}222 \text { nurses and } 126 \text { doctors } \\
\text { involved in the management } \\
\text { of PLWHA }\end{array}$ & $\begin{array}{l}\text { Low level on the knowledge of PC was reported. } \\
\text { Training on PC were associated with knowledge } \\
\text { and practice of PC. Attitude was positive in the } \\
\text { majority of the participant. }\end{array}$ \\
\hline
\end{tabular}




\section{Quality Assessment}

The final articles included in this review were assessed for quality using Hawker et al.'s (2002) critical appraisal tool. The aspects of a study that this tool assesses are the abstract and title, introduction and objectives, methodology, sampling techniques, data analysis, ethics/ biases, findings/results, generalizations, usefulness, and implications. Each element was evaluated and given a score between 1 (poor quality) and 4 (high quality). The highest possible score was 36 points. After scoring each element, the total score was obtained and allocated to a score range for overall quality as follows: poor (9-18 points), fair (19-27 points), or good (28-36 points). All the articles reviewed were considered good quality by this assessment, with the exception of two studies, which were only fair in quality due to issues with implications and usefulness (Table1).

Table 1: Quality scoring system.

\begin{tabular}{|c|c|c|c|c|c|c|c|c|c|c|c|}
\hline Authors & $\begin{array}{c}\text { Abst- } \\
\text { ract }\end{array}$ & $\begin{array}{l}\text { Intro- } \\
\text { duction } \\
\text { Objects }\end{array}$ & $\begin{array}{l}\text { Metho- } \\
\text { dology }\end{array}$ & $\begin{array}{l}\text { Sam- } \\
\text { Pling }\end{array}$ & $\begin{array}{c}\text { Data } \\
\text { analysis }\end{array}$ & $\begin{array}{l}\text { Ethics } \\
\text { and } \\
\text { Bias }\end{array}$ & $\begin{array}{l}\text { Finding-G } \\
\text { Result }\end{array}$ & $\begin{array}{l}\text { Genera- } \\
\text { lization }\end{array}$ & $\begin{array}{c}\text { Implicate- } \\
\text { On/Useful- } \\
\text { Ness }\end{array}$ & Total & \\
\hline Kim S [14] & 4 & 4 & 4 & 4 & 4 & 4 & 4 & 3 & 3 & 34 & Good \\
\hline Schnell [13] & 4 & 2 & 4 & 4 & 4 & 4 & 4 & 3 & 3 & 32 & Good \\
\hline Zeru [10] & 4 & 4 & 4 & 4 & 4 & 3 & 4 & 3 & 3 & 28 & Good \\
\hline J Kim [7] & 4 & 4 & 4 & 4 & 4 & 3 & 4 & 2 & 3 & 32 & Good \\
\hline Paknejadi [9] & 4 & 4 & 3 & 4 & 4 & 2 & 3 & 2 & 1 & 27 & Fair \\
\hline Wang [15] & 4 & 4 & 4 & 4 & 4 & 3 & 4 & 3 & 4 & 34 & Good \\
\hline Etafa [4] & 4 & 4 & 4 & 4 & 3 & 3 & 4 & 3 & 2 & 31 & Good \\
\hline Aboshaiqah [11] & 4 & 4 & 4 & 4 & 3 & 3 & 4 & 3 & 3 & 33 & Good \\
\hline $\mathrm{Vu}[17]$ & 4 & 3 & 3 & 4 & 4 & 4 & 4 & 3 & 2 & 30 & Good \\
\hline Abate [16] & 4 & 3 & 4 & 4 & 4 & 3 & 4 & 3 & 3 & 32 & Good \\
\hline Wilson [9] & 4 & 3 & 3 & 3 & 4 & 4 & 4 & 3 & 2 & 30 & Good \\
\hline Ajisegiri [3] & 4 & 4 & 3 & 3 & 4 & 2 & 3 & 2 & 2 & 27 & Fair \\
\hline
\end{tabular}

\section{RESULTS}

From the database, a total of 616 studies (2016-2020) were found through search databases. After duplicates removed, 446 articles were remained. Then, the titles and abstracts of the remaining 446 articles were screened manually by the researchers. After applying the inclusion and exclusion criteria, the search was narrowed to 157 studies. These studies' full-text articles were further screened in-depth to determine a study's relevance. Therefore, only 12 studies were found fit to be used in this review (Figure 1).

\section{Characteristics of the Reviewed Studies}

Twelve studies were retrieved that assessed nurses' level of knowledge and attitudes towards PC and the factors affecting their knowledge and attitudes. The analyzed studies were all published between 2016 and 2020. All adopted a descriptive, cross-sectional design. The study populations consisted of ICU nurses general ward nurses Wang [15]; Abate [16]; Vu [17]. The smallest sample consisted of 61 nurses in the study conducted by Wilson et al. (9). The largest sample was of 770 nurses in the study by the studies were conducted in various geographical locations, including China Ethiopia Etafa [4]; Zeru [10], Canada Schnell [13], Iran Paknejadi [8], South Korea S Kim [14], Saudi Arabia Aboshaiqah [11], Mongolia J Kim [7], Ireland Wilson [9], Nigeria Ajisergiri [3], Etnam Vu; Abate et al.[16]; Vi et al. [17].

\section{Tools Used to Assess Nurses' Knowledge and Attitudes Towards Palliative Care}

The most frequently used tool was the 20 -item Palliative Care
Quiz for Nursing (PCQN), which assesses nurses' knowledge about PC Wilson [9]; Schnell [13]; Aboshaiqah [11]; Ajisegiri [3]; Paknejadi [8]; Etafa [4]; J Kim [7]; S Kim [14]; Zeru [10]. The PCQN evaluates knowledge in three domains: the philosophy and principles of PC (four items); management of pain and other symptoms (13 items); provision of psychosocial and spiritual care (three items).

Another tool used to assess knowledge was the Palliative Care Knowledge Test (PCKT) Vu [17]. This is also a 20-item measure. It tests knowledge in five areas: gastrointestinal issues (four items), psychiatric issues (four items), dyspnea (four items), pain (six items), and PC philosophy (two items). The End-of-Life Knowledge Assessment for nurses was used in one study, it is a 24-item tool measure the 'end of life care' knowledge of nurses Abate [16]

Regarding the attitudes of nurses toward PC, the Frommelt Attitudes Toward Care of the Dying (FATCOD) 30-item scale was the most commonly utilized Wang [15]; Abate [16]; Ajisegiri [3]; Vu [17]; Etafa [4]; Kim [7]; Kim [14]; Zeru [10]. FATCOD assesses feelings, thoughts, and attitudes about PC and comfort levels in practicing PC. Twenty items address attitudes toward patients and ten address attitudes toward families of patients.

Another tool used was the seven-item Thanatophobia Scale was used in one study to evaluate attitudes towards caring for dying patients Wilson [9].

\section{DISCUSSION}

\section{Level of Knowledge About Palliative Care}

In total, twelve studies examined nurses' knowledge about PC was included in this review. All studies consistently found that 
nurses have limited or inadequate knowledge about palliative care. This strongly indicates a need for revisions to nurses training and education to address this deficit of the twelve reviewed studies, only one study reported a moderate level of knowledge about PC Wilson [9].

The study by Etafa [4] assessed 422 nurses' knowledge and attitudes about PC in public hospitals in Ethiopia found that most of the nurses had inadequate PC knowledge. The mean PCQN score was 9.34 out of 20 . Only $52 \%$ of these nurses indicated that they were willing to care for the critically ill and their relatives.

Paknejadi [8] also used the PCQN. A sample of 280 nurses in Iran was evaluated on their PC knowledge. The mean score of participants in this study was 7.86 out of 20, indicating poor knowledge levels.

Kim [7] indicate that an understanding of palliative care knowledge levels and attitudes among nurses is an indication of their preparedness to provide the required care. A cross sectional descriptive study conducted among a sample of nurses providing palliative care in Mongolia, it was determined that median score for knowledge is $8 / 20$. These results show that there are knowledge gaps among nurses providing palliative care, and this has negative implications for practice Kim [7].

These findings are consistent with another study in Ethiopia Zeru [10] tested 355 nurses from six government hospitals. They found good knowledge of PC in only $62.8 \%$ of their sample.

In the same line, $\mathrm{Vu}$ [17] assessed health professionals' knowledge about and attitudes toward PC in geriatric care in Vietnam. A sample of 161 doctors and nurses working in geriatric care in Vietnam were assessed. Data was collected using the FATCOD scale and the PCKT. Inadequate knowledge of PC was displayed by $74.2 \%$ of the nurses in the study.

Aboshaiqah [11] conducted a study in Saudi Arabia with the intention of assessing the palliative care knowledge among nurses with a focus on identifying the demographic factors that influence the knowledge levels. The study reported low knowledge levels among nurses (only $11.2 \%$ of participants scored above the midpoint). A Canadian study Schnell [13] explored knowledge about PC in 126 cardiac nurses. It was noted that, while there is an increasing need for nurses to provide palliative care, the nurses in the sample appeared unprepared to meet this need, having limited knowledge about palliative care. In contrast to the other studies reviewed, A study in Ireland explored the knowledge of 61 nurses providing PC to older persons reported a moderate level of PC knowledge among the nurses tested Wilson [11].

\section{Knowledge Deficits Area}

Despite a variety of tool for assessing palliative care knowledge among nurses, most of the findings suggest a general lack of knowledge in three areas of PC: philosophy and principle of PC, the psychosocial and spiritual aspects of care, and the management of pain and other symptoms.

Schenell [13] and Wilson [9] found knowledge deficits and misconceptions among nurses about PC philosophy. Moreover, they revealed that the greatest percentage of incorrect answers in these studies was to questions about the philosophy of PC. The finding by $\mathrm{Vu}$ [17] differs from the findings of the above mention studies. The author presented lack of PC knowledge in management of pain and other symptom domain as the lowest scores was scored in the management of pain, dyspnea and gastrointestinal symptoms. While satisfactory level was obtained on the philosophy of PC area.

Aboshaiqah [11], on the other hand, found knowledge of symptom and pain management to be adequate in most of his sample, while knowledge of the spiritual and psychosocial aspects of PC was inadequate in most nurses (incorrect response range $=78.6$ to $93.4 \%$ ) (2020) obtained a similar result, with nurses scoring particularly poorly on questions about the spiritual and psychosocial aspects of PC.

While Paknejadi [8] reported poor knowledge among nurses on all three of these components of PC knowledge: psychosocial aspects of care, the philosophy and principles of PC, and management of pain and other symptoms.

\section{Factors Affecting Nurses Knowledge About Palliative Care}

Numerous factors have been proposed as potential influences on nurses' knowledge about PC. The department in which a nurse practices and their professional training background were significantly associated with knowledge of Zeru [10].

Furthermore, the PC knowledge levels are influenced by educational level, age, and the type of facility. Aboshaiqah [11] determined that nurses who received PC education in the six months prior to the study had significantly higher scores on a test of PC knowledge (mean score 9.14, SD 1.71) than their counterparts who did not (mean score 8.37, SD 1.73) $(\mathrm{t}=-4.04, p<.001)$. Moreover, Older nurses (40 years and over) had significantly higher scores (mean score 9.44, SD 1.98) than their younger counterparts (mean score 8.62, SD 1.70) $(p<.008)$ Aboshaiqah [11].

Besides that, Wilson [9] revealed that more time spent practicing as a nurse improves knowledge levels towards palliative care. Additionally, the researchers noted that nurses who completed formal training on palliative care were more knowledgeable and had better attitudes than nurses who did not complete formal training.

\section{Nurses Attitudes Toward Palliative Care}

Nurses' attitudes toward PC can have a major impact on the quality of the care patients receive. Among the articles in this review, the attitudes of nurses toward PC varied from positive, to moderate, to negative, with the majority having a more positive attitude. In most of the studies reviewed, nurses were found to have a positive attitude toward PC or caring for terminally ill patients Abate [16]; Kim [14]; Ajisegiri [3]; Etafa [4]; J Kim [7]; Kim [14]; Vu [17]; Zeru [10].

Kim [14] examined knowledge, attitudes, and self-efficiency related to PC among nurses in Mongolia using FATCOD and found that most nurses have positive attitudes toward PC. This finding is consistent with that of Etafa [4], 79.8\% of the participants demonstrated positive attitudes towards PC. Abate [16] also found $70.7 \%$ of participants to have favorable attitudes towards end of life (EOL) care.

Wilson [9] assessed the attitude of nurses toward PC using Thanatophobia Scale and found that most of nurses had favorable attitude towards caring for the dying.

On the other hand, two studies reported moderate attitudes 
toward PC among nurses Wang [15]; Kim [14]. The first of these was conducted in China Wang [15] and gathered data from 770 nurses, using FATCOD. Nurses' attitudes toward PC were moderately positive. The second study, by Kim [17], examined the PC knowledge, attitudes, and educational needs of 120 nurses caring for non-oncology patients in the general ward hospitals in Korea. This study found moderate attitudes towards PC of nononcology patients among the sample of nurses.

\section{Factors Affecting Nursing Attitudes Toward Palliative Care}

Many factors have been identified as potential contributors to the attitudes of nurses toward caring for palliative patients. It has been established that nurses' attitudes towards the terminally ill are dependent on their level of education, fear of death, age, previous training in caring for dying persons, and their professional title Wang [15]. Furthermore, Wang [15] found that nurses who had attended PC training sessions had more positive attitudes.

Similarly, Wilson [9] have demonstrated that nurses' attitudes towards PC improve with their level of education. Abate [16] found that nurses with 6-10 years of experience in nursing, trained in PC, and with a bachelor's degree in nursing have more positive attitudes towards PC than less experienced, less educated nurses. Ajisegiri [3] also supported that work experience were significantly associated with more positive attitude toward palliative care. The attitudes of nurses were influenced by age; older nurses had more favorable attitudes towards the caring of dying patients and their families in general Wilson [9].

\section{IMPLICATIONS}

With the increasing number of non-communicable and lifethreatening diseases all over the world today like cancer and cardiovascular diseases, PC is needed, and the demand is likely to increase in the coming years. It is therefore important that nurses have the necessary training and adopt positive attitudes required to deliver PC as it is important to improve the quality of life of not only the patient but also the family in general. An integrated approach to PC nursing needs to be created across different health care levels (primary level, secondary level, and tertiary level). Without specific policies, clinical recommendations, and standardized procedures, PC cannot be well incorporated into the health care system. leader nurses should work with the health authorities to design strategies that guide the delivery of PC at the bedside. The findings of this review have implications for health policy, nursing practice, and nursing education. There is an urgent need to provide continuing education and training sessions in PC to improve nurses' PC knowledge, attitudes, and skills and equip them with the competence to provide high-quality care to palliative patients. Furthermore, the addition of a mandatory module on palliative or EOL care to the nurse training curriculum is necessary to prepare nursing students to effectively deliver such care to patients.

\section{CONCLUSION}

This review offered a valuable overview of palliative care nursing. It is evident that health care professionals, and nurses, in particular, lack adequate knowledge of PC, which impacts their ability to provide it or to offer quality EOL care to palliative patients. In contrast, nurses' attitudes towards PC were shown to be favorable, although there is an increasing need to implement strategies to improve these attitudes as well as Knowledge. The research included in this review recommends the implementation of policies that underscore the importance of PC and mandate PC education in nurse training curricula and in employee training approaches within organizations.

\section{REFERENCES}

1. World Health Organization (2014) Strengthening of palliative care as a component of integrated treatment throughout the life course. J Pain \& Palliative Care Pharmacotherapy 28(2): 130-134

2. Worldwide Palliative Care Alliance \& World Health Organization (2014) Global atlas of palliative care at the end of life. Worldwide Palliative Care Alliance.

3. Ajisegiri WS, Abubakar AA, Gobir AA, Balogun MS, Sabitu K, et al. (2019) Palliative care for people living with HIV/AIDS: Factors influencing healthcare workers' knowledge, attitude and practice in public health facilities, Abuja, Nigeria. PloS One 14(12): e0207499.

4. Etafa W, Wakuma B, Fetensa G, Tsegaye R, Abdisa E, et al. (2020) Nurses' knowledge about palliative care and attitude towards end- of-life care in public hospitals in Wollega zones: A multicenter cross-sectional study. PLoS ONE 15(10): e0238357.

5. Ansari M, Rassouli M (2018) Team approach in palliative care: A narrative review. Basic \& Clinical Cancer Research 10(1): 42-48.

6. Gopal KS, Archana PS (2016) Awareness, knowledge and attitude about palliative care, in general, population and health care professionals in tertiary care hospital. Int J Sci Stud 3(10): 31-35.

7. Kim JS, Kim J, Gelegjamts D (2020) Knowledge, attitude and self-efficacy towards palliative care among nurses in Mongolia: A cross-sectional descriptive study. PloS one 15(7): e0236390.

8. Paknejadi F, Hasavari F, Mohammadi T, Leili E (2019) Nurses' knowledge of palliative care and Iits related factors. J Holist Nurs Midwifery 29(4): 236-242.

9. Wilson O, Avalos G, Dowling M (2016) Knowledge of palliative care and attitudes towards nursing the dying patient. British J Nursing (BJN) 25(11).

10. Zeru T, Berihu H, Gerensea H, Teklay G, Teklu T, et al. (2020) Assessment of knowledge and attitude towards palliative care and associated factors among nurses working in selected Tigray hospitals, northern Ethiopia: A cross-sectional study. Pan African Medical J 35: 121.

11. Aboshaiqah AE (2019) Assessing palliative care knowledge among nurses in 2 hospitals in saudi arabia. J Hospice \& Palliative Nursing 21(3): E1-E6.

12. Göriș S, Tașcı S, Özkan B, Ceyhan Ö, Kartın PT, et al. (2017) Effect of terminal patient care training on the nurses' attitudes toward death in an oncology hospital in turkey. Journal of cancer education: the official J American Association for Cancer Education 32(1): 65-71.

13. Schnell HK, Estrella HE, Avery L (2017) Cardiac nurses' knowledge of palliative care. Canadian J Cardiovascular Nursing 27(4): 9-15.

14. Kim S, Lee K, Kim S (2020) Knowledge, attitude, confidence, and educational needs of palliative care in nurses caring for non-cancer patients: a cross-sectional, descriptive study. BMC Palliative Care 19(1): 105.

15. Wang L, Li C, Zhang Q Li Y (2018) Clinical nurses' attitudes towards death and caring for dying patients in China. International J Palliative Nursing 24(1): 33-39.

16. Abate AT, Amdie FZ, Bayu NH, Gebeyehu D, Mariam T (2019) Knowledge, attitude and associated factors towards end-of-life care among nurses' working in Amhara Referral Hospitals, Northwest Ethiopia: a crosssectional study. BMC Research Notes 12(1): 521.

17. Vu H, Nguyen L, Nguyen T, Nguyen T, Nguyen T, et al. (2019) Knowledge and attitude toward geriatric palliative care among health professionals in Vietnam. International J Environmental Research and Public Health 16: 2-11. 